\title{
Temporomandibular joint dysfunction in various rheumatic diseases
}

\author{
F.J. Aceves-Avila ${ }^{1,2}$, M. Chávez-López ${ }^{3}$, \\ J.R. Chavira-González ${ }^{4}$, C. Ramos-Remus ${ }^{2,5}$ \\ ${ }^{1}$ Hospital General Regional No. 46, Instituto Mexicano del Seguro Social, Guadalajara, Jalisco; \\ 2Unidad de Investigación en Enfermedades Crónico-Degenerativas S.C., Guadalajara, Jalisco; \\ ${ }^{3}$ Centenario Hospital "Miguel Hidalgo", Secretaría de Salud, Aguascalientes; \\ ${ }^{4}$ Centro Universitario de Ciencias de la Salud, Universidad de Guadalajara, Jalisco; \\ ${ }^{5}$ Hospital General De Zona No. 45, Instituto Mexicano del Seguro Social, Guadalajara, Jalisco, México
}

\section{SUMMARY}

Temporomandibular disorder (TMD) is an inclusive term in which those conditions disturbing the masticatory function are embraced. It has been estimated that 33\% of the population have signs of TMD, but less than 5\% of the population will require treatment. The objective of this study was to measure the frequency of TMD in rheumatoid arthritis (RA), osteoarthrosis (OA), ankylosing spondylitis (AS) and systemic lupus erythematosus, and to define the limitations in everyday's life that patients perceive when present.

A six-month survey of consecutive outpatients in a rheumatology clinic in a teaching hospital in Mexico was carried out. We defined TMD as:

1) the presence of pain;

2) difficulty on mouth opening, chewing or speaking;

3) the presence of non-harmonic movements of the temporomaxilar joints.

All three characteristics had to be present. $\mathrm{Z}$ test was used to define differences between proportions.

We present the results of 171 patients. Overall, 50 patients had TMD according to our operational definition (29.24\%). Up to $76 \%$ of the sample had symptoms associated with the condition. TMD is more frequent in OA and in AS $(29.24 \%$ vs $38 \% \mathrm{OA}, \mathrm{P}=0.009 ; 39 \% \mathrm{AS} ; \mathrm{P}=0.005)$. We found no association between the severity of TMD and the request for specific attention for the discomfort produced by the condition. Only 8 of 50 (16\%) patients with TMD had requested medical help for their symptoms, and they were not the most severe cases. TMD is more frequent in RA and OA. Although it may produce severe impairment, patients seem to adapt easily.

Key words: Temporomandibular joint dysfunction, Ankylosing spondylitis, Osteoarthrosis, Rheumatoid arthritis, Systemic lupus erythematosus.

Reumatismo, 2013; 65 (3): 126-130

Corresponding author: Francisco Javier Aceves-Avila Colomos 2292, Col. Providencia Guadalajara, Jalisco. México, CP 44620 E-mail: fjaceves@megared.net.mx

\section{INTRODUCTION}

T emporomandibular disorder (TMD) is an inclusive term in which those conditions disturbing the masticatory function are embraced. These conditions may be due to specific disorders of the temporomaxilar joints (TMJ), the masticatory muscles, or both. The most frequent presenting symptoms include pain in the TMJ, a clicking sensation in the TMJ, or pain in the masticatory muscles. It is frequently associated with limited mandibular movements, such as mouth opening and lateral movements on chewing. Headaches and muscular con- tractures in the cervical region are frequent associated complaints (1).

It has been estimated that $33 \%$ of the population have signs of TMD, but less than 5\% of the population will require treatment (2). TMJ is a synovial joint, and is the articulation between the base of the skull and the condyle of the mandible. It may be afflicted in juvenile rheumatoid arthritis, which may cause extensive resorption of the mandibular condyles. Erosions may be found in adult rheumatoid arthritis in severe cases. Due to the apparent dissimilar frequency of TMD associated with different rheumatic diseases, we conducted this survey. 
The transcendence of the condition in general rheumatologic practice is still debated. Most cases are diagnosed and treated by dentists and other medical practitioners associated with oral health, and are seldom initially diagnosed by rheumatologists.

\section{MATERIAL AND METHODS}

A survey was conducted in consecutive outpatients seen between September 2010 and February 2011 in the rheumatology clinic of a teaching hospital in Guadalajara, México. We only included patients with a definite diagnosis of rheumatoid arthritis (RA), ankylosing spondylitis (AS), osteoarthrosis (OA) or systemic lupus erythematosus (SLE).

To be included, the diagnosis had to be defined for at least two years, and all of them were attending on a regular basis to the rheumatology clinic. We intentionally excluded from the study patients with undifferentiated spondyloarthropathy.

All the patients included were surveyed for symptoms of TMD with a semistructured questionnaire (3) (Tab. I). In it, we also collected demographic information, and when symptoms were present, the severity of symptoms from the patient's perspective, the duration of symptoms and if the pa-

Table I - Screening questions for temporomandibular disorders.

\begin{tabular}{|l|}
\hline $\begin{array}{l}\text { 1. Do you have difficulty or pain, when opening your } \\
\text { mouth? }\end{array}$ \\
\hline 2. Does your jaw gets stuck, or locked or go out? \\
\hline $\begin{array}{l}\text { 3. Do you have difficulty or pain, when chewing, } \\
\text { talking or using your jaws? }\end{array}$ \\
\hline 4. Are you aware of noises in the jaw joint? \\
\hline 5. Does your bite feels uncomfortable or unusual? \\
\hline
\end{tabular}

Modified from Atsü and Ayhan-Ardic, 2006 (3). tients had asked for help due to the symptoms in previous consultations.

The use of prosthetic oral devices, the absence of dental pieces and previous surgical procedures in mouth or neck were recorded.

All the patients included were also assessed for TMD by physical examination involving palpation of muscles around the TMJ, palpation of both TMJ at rest and during motion, and movement of TMJ.

We defined TMD as

1) the presence of pain;

2) difficulty on mouth opening, chewing or speaking;

$3)$ the presence of non-harmonic movements of the TMJ.

All three characteristics had to be present to include the patient as having TMD.

We used $\mathrm{z}$ test for independent proportions to identify differences between groups The null hypothesis for the test assumes that each sample comes from populations with the same proportion of the measured condition (4).

\section{RESULTS}

We surveyed 200 consecutive outpatients. We excluded those patients with previous temporomaxilar surgery and prosthetic use (5). We present the results of 171 patients. Overall, 50 patients had TMD according to our operational definition (29.24\%). Up to $76 \%$ of the sample had symptoms associated with the condition but no clinical signs to fulfill our diagnostic requirements. The total number of patients with each diagnosis included and the frequencies of TMD are presented in Table II.

TMD seems to be more frequent in OA and in AS when comparing the relative fre-

Table II - Temporomandibular disorder in diverse rheumatic conditions.

\begin{tabular}{|l|l|l|l|l|}
\hline Diagnosis & With TMD & No TMD & Total & P \\
\hline Rheumatoid arthritis & $24(26 \%)$ & $68(74 \%)$ & 92 & n.s. \\
\hline Ankylosing spondylitis & $13(39 \%)$ & $20(61 \%)$ & 33 & 0.005 \\
\hline $\begin{array}{l}\text { Systemic lupus } \\
\text { erythematosus }\end{array}$ & $5(20 \%)$ & $20(80 \%)$ & 25 & n.s. \\
\hline Osteoarthrosis & $8(38 \%)$ & $13(62 \%)$ & 21 & 0.009 \\
\hline
\end{tabular}

TMD, temporomandibular disorder; n.s., non-significant. 


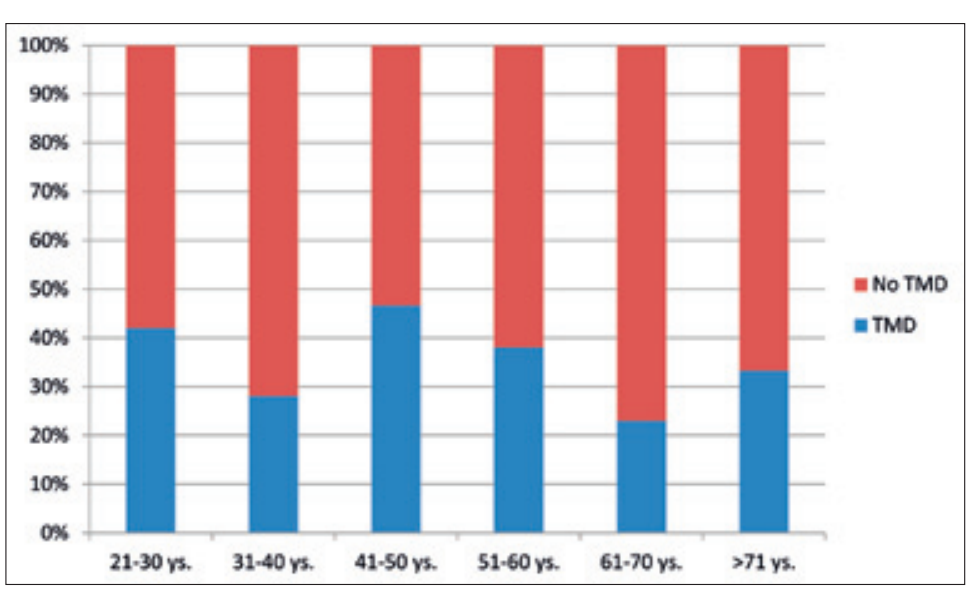

Figure 1 - Temporomandibular disorder (TMD) frequency in diverse age groups (ys.).

\section{DISCUSSION}

The correct function of the TMJ is of utmost importance since severe impairment may difficult some basic human functions such as feeding or communication. Although symptoms are frequent in open populations, clinical signs are rare. TMJ may be a consequence of previous damage by causes other than diseases. Patients with previous surgical procedures and use of diverse oral appliances were excluded from our sample.

This was done as an effort to assure that any changes found could be more easily associated with the primary disease.

The general frequency of TMD in our sample $(29.24 \%)$ is similar to the frequency reported in open populations, which is around $33 \%$ (2). We found a higher than expected frequency of TMD in primary OA and in AS. TMD has been reported as a frequent condition in AS when compared with a control group of people with no known rheumatic conditions (6). It has also been associated with RA (7). However, in RA populations, the radiographic changes found in those patients with TMJ seem to be due to osteoarthrosis and not to specific damage induced by RA $(8,9)$. TMD in AS could be a particular manifestation of the pathogenic process of the disease, based on the frequencies found in our group of patients and a reported higher frequency of symptoms in patients with AS and undifferentiated spondyloarthropathy as compared with RA and mixed connective tissue disease reported by Helenius et al. (10). This possibility warrants further investigations. TMD has not been identified as a frequent cause of symptoms in SLE, and the radiographic changes reported in the condition,

Table III - Temporomandibular disorder frequency by diagnosis and age group.

\begin{tabular}{|c|c|c|c|c|c|c|}
\hline Diagnosis & $\begin{array}{l}21-30 \\
\text { years }\end{array}$ & $\begin{array}{l}31-40 \\
\text { years }\end{array}$ & $\begin{array}{l}41-50 \\
\text { years }\end{array}$ & $\begin{array}{l}51-60 \\
\text { years }\end{array}$ & $\begin{array}{l}61-70 \\
\text { years }\end{array}$ & $\begin{array}{l}>71 \\
\text { years } \\
\end{array}$ \\
\hline Rheumatoid arthritis & $40 \%$ & $50 \%$ & $53 \%$ & $30 \%$ & $66 \%$ & $25 \%$ \\
\hline Ankylosing spondylitis & $20 \%$ & $30 \%$ & $34 \%$ & $20 \%$ & 0 & 0 \\
\hline Systemic lupus erythematosus & $40 \%$ & $20 \%$ & $13 \%$ & $0 \%$ & 0 & 0 \\
\hline Osteoarthrosis & 0 & 0 & 0 & $50 \%$ & $34 \%$ & $75 \%$ \\
\hline Total & $100 \%$ & $100 \%$ & $100 \%$ & $100 \%$ & $100 \%$ & $100 \%$ \\
\hline
\end{tabular}


as in RA, seem to be due to osteoarthrosis (11).

We intentionally excluded patients with undifferentiated spondyloarthropaty, reactive arthritis, spondyloarthropaty associated with psoriasis and spondyloarthropaty associated with inflammatory intestinal disease. Still, we found a higher than expected frequency of TMD in AS patients. AS is the disease we consider as most representative of this group of conditions. Most of the damage until now considered as cause of TMD is described as associated with the joint itself, or with alterations in the muscles associated with its correct functioning, but seldom attention has been placed in the tendinous system. There is a good chance that the higher frequency of symptoms and signs of TMD seen in this group of patients could be caused by the direct pathogenic effect of AS in the tendinous system in the TMJ. An interesting observation emerging from our data is that in AS, TMD seems to be present in the first years of disease presentation, and it lowers its incidence as the original disease diminishes its activity, as can be seen in Figure 1.

Despite the severe functional limitation found in some of our patients, it was surprising to notice that those patients with the most severe forms of TMD have not consulted with the rheumatologist, their regular dentist or primary physician for advice on treatment. In fact, they were not especially worried about this specific functional limitation.

At least in RA, there is previous evidence that pain and discomfort associated with TMJ dysfunction are higher during extreme mouth opening, and reach their lower levels during eating (12). Patients with temporomandibular disorders modify their eating habits to adapt to the limitations provoked by their condition (13). Thus, in the patient's perspective, it does not seem to be a serious problem in the long term. This functional adaptation could account for the lack of interest most patients show for this condition. Most authors report that female patients seek care for this condition more frequently than males. We did not found this to be the case.

\section{CONCLUSIONS}

How to treat this condition? We believe treatment should be offered to those patients who complain of important discomfort. To date, several treatment options are available (14). Most patients with TMD associated with rheumatic diseases achieve good symptom relief with conservative treatments (3). In most of our patients, TMD was an incidental finding due to the intentional search for the condition.

Conflict of interests: the authors declare no potential conflict of interests.

\section{REFERENCES}

1. Dolwick MF. Clinical diagnosis of temporomandibular joint internal derangement and myofascial pain and dysfunction. Oral Maxillofac Surg Clin North Am. 1989; 1: 1-16.

2. Dolwick MF. Temporomandibular disorders. In: WJ Koopman, LW Moreland, eds. Arthritis and allied conditions. A textbook of rheumatology. Philadelphia, PA: Lippincott Williams \& Wilkins; 2005; 2065.

3. Atsü SS, Ayhan-Ardic F. Temporomandibular disorders seen in rheumatology practices: a review. Rheumatol Int. 2006; 26: 781-7.

4. Dawson B, Trapp RG, eds. Basic and clinical biostatistics. London: Lange Medical Books/ Mc Graw Hill; 2001.

5. Gleissner C, Kaesser U, Dehne F, et al. Temporomandibular joint function in patients with longstanding rheumatoid arthritis. I. Role of periodontal status and prosthetic care-a clinical study. Eur J Med Res. 2003; 8: 98-108.

6. Major P, Ramos-Remus C, Suarez-Almazor $\mathrm{ME}$, et al. Magnetic resonance imaging and clinical assessment of temporomandibular joint pathology in ankylosing spondylitis. J Rheumatol. 1999; 26: 616-21.

7. Laskin DM. Temporomandibular joint pain. In: ED Harris, RC Budd, GS Firestein, et al., eds. Kelley's textbook of rheumatology. Philadelphia, PA: Elseiver Saunders; 2005; 721-32.

8. Koh ET, Yap AU, Koh CK, et al. Temporomandibular disorders in rheumatoid arthritis. J Rheumatol. 1999; 26: 1918-22.

9. Bayar N, Kara SA, Keles I, et al. Temporomandibular joint involvement in rheumatoid arthritis: a radiological and clinical study. Cranio. 2002; 20: 105-10.

10. Helenius LM, Hallikainen D, Helenius I, et al. Clinical and radiographic findings of the temporomandibular joint in patients with various 
rheumatic diseases. A case-control study. Oral Surg Oral Med Oral Pathol Oral Radiol Endod. 2005; 99: 455-63.

11. Wallace DJ. The musculoskeletal system. In: DJ Wallace, BV Hahn, eds. Dubois' lupus erythematosus. Philadelphia, PA: Lippincott Williams \& Wilkins; 2002; 631.

12. Voog U, Alstergren P, Leibur E, et al. Impact of temporomandibular joint pain on activities of daily living in patients with rheumatoid ar- thritis. Acta Odontol Scand. 2003; 61: 278-82.

13. Haketa T, Kino K, Sugisaki M, et al. Difficulty of food intake in patients with temporomandibular disorders. Int J Prosthodont. 2006; 19 : 266-70.

14. List T, Axelsson S, Leijon G. Pharmacologic interventions in the treatment of temporomandibular disorders, atypical facial pain, and burning mouth syndrome. A qualitative systematic review. J Orofacial Pain. 2003; 17: 301-10. 